\title{
EFECTOS DIRECTOS DEL CONFLICTO ARMADO EN LA REGIÓN DEL CATATUMBO: DESPLAZAMIENTO, PÉRDIDA DE CAPITAL HUMANO Y ALTERACIÓN EN EL MERCADO LABORAL
}

Nora Marcela Jaimes Méndez*

* Investigadora Instituto de Investigaciones ICEE, Facultad de Ciencias Económicas y Empresariales, Universidad de Pamplona. E-mail: nobri@unipamplona.edu.co 


\section{EFECTOS DIRECTOS DEL CONFLICTO ARMADO EN LA REGIÓN DEL CATATUMBO: DESPLAZAMIENTO, PÉRDIDA DE CAPITAL HUMANO Y ALTERACIÓN EN EL MERCADO LABORAL}

\section{RESUMEN}

El conflicto armado en Colombia es un fenómeno diferenciado temporal $y$ geográficamente, que permite evidenciar las problemáticas de las regiones tales como desigualdad, pobreza, desempleo, que facilitan y generan oportunidades para los diferentes actores armados, que fácilmente se insertan por medio de la violencia.

El desplazamiento en la región del Catatumbo, ha conllevado a una crisis humanitaria significativa, que incluye el desarraigo de familias, quienes pierden los vínculos sociales y la inserción en las redes sociales de la comunidad. Estos hogares desplazados carecen de mecanismos para mitigar y enfrentar las diferentes presiones de los grupos al margen de la ley con influencia en la zona.

A su vez, las consecuencias del desplazamiento se evidencian en la perdida del capital humano y en al alteración del mercado laboral, influyendo negativamente en el desarrollo de las libertades y autonomías, para lograr lo que la población juzga valioso para el disfrute de una vida más digna y más justa.

Palabras Claves: Conflicto armado, desplazamiento, Región Catatumbo, libertad, bienestar, capital humano, mercado laboral.

\begin{abstract}
The armed conflict in Colombia is geographical with its temporal differences that permit the problems in the regions to give their evidence; such as: inequality, poverty, unemployment that facilitate and generate opportunities for armed groups to insert themselves by means of violence.

Displaced people in the region of 'Catatumbo' has brought with it, a very serious humanitarian crisis including the uprooting of families losing their social ties and the placement of these people in their social network in the community. These homes lack the mechanisms to mitigate and confront the different pressures of the illegal, marginal groups with that powerful influence in the zone.

At the same time there is an evidence of the loss of human capacities and the laboral market's alteration as a definite consequence influencing, therefore, the development of autonomous action and liberty as a negative consequence. These are only the basic rights the community judges to be of value in order to enjoy a dignified and just life.
\end{abstract}

Key Words: Armed Conflict, Displaced people, Región of 'Catatumbo', Liberty, Wellbeing, Human capacities, Labor Market. 


\section{INTRODUCCIÓN}

Es indudable que el conflicto armado es un problema significativo que afecta el desarrollo económico y social de las regiones que viven su influencia y la degradación de su entorno. Los estudios en cuanto a la medición de los costos causados por estas acciones violentas son muy escasos, pero se sabe que los costos económicos y sociales son bastante elevados, sin duda es mas desalentador saber que a pesar de esta situación tan critica no se ha establecido un análisis profundo que incluya a la violencia en las discusiones de políticas públicas como medio interventor para subsanar los efectos de este grave problema.

Es importante considerar el tema del desplazamiento por causa del conflicto armado como un fenómeno social que va en detrimento de la población que la padece.

Durante los últimos años, la región del Catatumbo ha sido una de las más afectadas por la actividad de los actores armados de Colombia, especialmente por su ubicación geográfica y la lucha incesante de espacios óptimos y estratégicos para los cultivos ilícitos. Esta situación se ha manifestado en una difícil problemática de orden público, que se proyecta principalmente en el área del Catatumbo.

La finalidad de este artículo responde a la metodología descriptiva e interpretativa siguiendo una línea cronológica que permite la explicación de la temática que objeto de estudio.

Resulta de gran importancia describir brevemente la evolución del conflicto armado en Colombia, desde el ámbito nacional y regional, específicamente la zona del Catatumbo Colombiano, haciendo énfasis en la población desplazada, como un fenómeno social critico que impide el desarrollo de las libertades, la expresión de los derechos y de la autonomía, generando perdida de capital humano y alteración en el mercado laboral.

\section{EVOLUCIÓN DEL CONFLICTO ARMADO}

\section{Colombia}

En los últimos años la dinámica del conflicto armado colombiano ha cambiado considerablemente. A comienzos de los ochenta el fenómeno se limitaba a algunas zonas rurales, especialmente a las áreas de colonización, y punto de partida de la organización campesina pero, desde mediados de la década de los ochenta se ha presentado un crecimiento continuo de la actividad de los grupos armados al margen de la ley junto con una expansión territorial de los mismos. 


\section{Norte de Santander}

El Eln fue la primera guerrilla en hacer su aparición en Norte de Santander, aprovechando su localización fronteriza, su condición petrolera y más tarde debido a la construcción del oleoducto Caño Limón Coveñas. Logró, con el tiempo, arraigarse con especial fuerza en el Catatumbo, el Sarare, en la Provincia de Ocaña y en el área metropolitana de Cúcuta.

Hay que aclarar que Norte de Santander tuvo un pasado petrolero que facilitó la implantación del Eln. La exploración petrolera en el Catatumbo data de principios del siglo XX, la cual se dio sobre todo a partir de los años cuarenta y con un mayor auge a mitad de los sesenta. Después de presiones sociales organizadas por la $\mathrm{USO}^{1}$, el campo revirtió a la Nación en 1976 y ECOPETROL asumió su explotación cuando la producción empezó a declinar. Se crearon varios frentes que nacieron y se fortalecieron alrededor del oleoducto Caño Limón Coveñas. Es importante destacar que oleoducto explica el surgimiento de Eln al igual que su fortalecimiento económico durante los 80 y parte de los 90 .

Durante los ochenta y parte de los noventa el Eln era la principal organización guerrillera pero paulatinamente empezó a perder su predominio conjuntamente con el fortalecimiento de las Farc y las actuaciones de las autodefensas, ambas organizaciones crecieron estrechamente relacionadas con los cultivos ilícitos. El Eln, golpeado por la Fuerza Pública, de un lado, y debilitado por las estructuras de autodefensas, del otro, se ha replegado en las zonas montañosas y selváticas en donde ha buscado el apoyo de las Farc.

Las Farc llegaron al departamento a través del frente 33 después de la denominada Séptima Conferencia (1982), nacieron en Norte de Santander en un momento de gran expansión a nivel nacional, ésta organización tenía como uno de sus propósitos abarcar la Cordillera Oriental creando una cadena de frentes que unieran al Ecuador con Venezuela. El fortalecimiento de las Farc estuvo íntimamente relacionado con los cultivos de coca y el procesamiento del alcaloide, principalmente en la región del Catatumbo. Si bien los cultivos se remontan a mediados de los ochenta, a partir de 1996 la producción experimentó un auge, expandiéndose por toda la región elevando significativamente indicadores de violencia en los últimos años.

Sin duda alguna las Auc, Autodefensas Unidas de Colombia, son hoy en día una organización de más poderío y cuenta con gran presencia en el departamento de Norte de Santander. Su llegada al departamento se produce en los 80 en la provincia de Ocaña, estrechamente relacionada con la violencia que se producía en el sur del Cesar y quienes tenían como propósito debilitar al Eln golpeando sus bases de apoyo.

\footnotetext{
1 Unión Sindical Obrera de la Industria de Petróleo.
} 
En 1999 incursionan desde el Cesar hacia Norte de Santander, esta nueva estructura denominada Bc, articulado al bloque norte de la Auc, se acento en Tibú, y fue aumentando su influencia paulatinamente hacia municipios vecinos. Esto sin duda alguna tenia unos intereses bien claros dominar el corredor Tibú-Puerto SantanderCúcuta y asegurar la comunicación con el Urabá, Córdoba, y Arauca trazando una línea divisoria entre norte y centro del país. Una de las agrupaciones, en especial las Farc, se encargaba de colonizar y detrás de esta venía la otra, con el propósito de apropiarse de la cosecha y después de los cultivos.

\section{CONSECUENCIAS DEL CONFLICTO ARMADO EN LA REGIÓN DEL CATATUMBO}

\section{Desplazamiento}

La intensificación del conflicto armado y su expansión territorial producen un incremento en el número de víctimas civiles, las estrategias de los grupos armados y la necesidad de financiar sus operaciones derivan en prácticas tales como el secuestro, las masacres, los asesinatos selectivos, las órdenes de desalojo y el reclutamiento forzoso, entre otros.

El desplazamiento forzoso de poblaciones, consecuencia de dichas acciones, constituye una de las expresiones más dramáticas del conflicto Armado en la región del Catatumbo. El desplazamiento forzoso es una de las crisis humanitarias y sociales más profundas que enfrenta el país, tanto por los costos que impone al Estado y a la sociedad, como por los efectos en la calidad de vida de quienes enfrentan el desplazamiento.

El desplazamiento constituye un choque tan fuerte en las vidas de quienes lo padecen, que tardan años en recuperarse. Se ha calculado que los hogares desplazados pierden cerca del 25\% del bienestar de su ciclo de vida y tardan más de nueve años en alcanzar niveles de vida similares a los de los migrantes voluntarios con iguales características (Ibáñez, Vélez, y Neira, 2004).

La salida intempestiva del lugar de origen obliga a las víctimas del desplazamiento a abandonar sus activos, tales como las tierras, las inversiones en sus predios y la vivienda, entre otros. Además pierden vínculos sociales, inserción en las redes sociales con la comunidad, perdiendo así los mecanismos informales para mitigar choques. El proceso de asentamiento en el municipio receptor es, además, lento debido a la dificultad para generar nuevas alternativas de ingresos. 
Dadas las altas tasas de desempleo en las áreas urbanas y la baja dotación de capital humano de la población desplazada, los mercados laborales urbanos no absorben tales flujos de población de manera inmediata. La iniciación de proyectos productivos es pocas veces una opción, pues la pérdida de capital como consecuencia del desplazamiento impide contar con un capital para invertir. Todo lo anterior ocasiona unas condiciones de vida sumamente precarias para la población desplazada.

Las cifras sobre el desplazamiento forzoso ${ }^{2}$ en la región del Catatumbo son preocupantes, los desplazamientos de población como consecuencia de las acciones del conflicto armado han sido numerosos. Según la defensoría del Pueblo, con base en información de la Red de Solidaridad Social, entre 1998, año en el que se dispararon los desplazamientos en Norte de Santander, y mediados de 2003, se desplazaron 7,837 hogares que suman 38,524 personas. El municipio de Tibú, se registra con 13,991 desplazados que representan el 36\% del total y El Tarra, con 7,216 es decir el 18\%, aparecen como los municipios más expulsores, situación entendible pues es en ellos donde los grupos irregulares, incluidas las autodefensas, han actuado con mayor intensidad, al tiempo que es donde hay la mayor cantidad de cultivos de coca. Así mismo se han venido presentando desplazamiento en los municipios de Convención, El Carmen, San Calixto y Teorama, en su conjunto el 17\%, de los municipios de la región del Catatumbo en donde la violencia se ha intensificado recientemente.

\section{Causas del desplazamiento}

Las causas del desplazamiento forzoso son complejas y tienen una relación estrecha y directa con el conflicto armado. Si bien en términos generales se reconoce al conflicto armado como la causa general del desplazamiento, es importante un análisis más detallado para comprender los diferentes elementos propios del conflicto que generan desplazamiento. En particular, la tenencia de la tierra, que constituye para muchos una prolongación de los conflictos agrarios del siglo pasado, y el narcotráfico, que tienen una relación estrecha en la actualidad con el conflicto armado debido a la lógica e intereses de los actores, son fundamentales para comprender el desplazamiento.

A su vez, es importante diferenciar las causas del desplazamiento de los detonantes específicos que generan el desplazamiento de los hogares así como los actores que a través de diferentes mecanismos expulsan a la población. En esta sección se describirán las diferentes causas y detonantes del desplazamiento y su relación con los actores

2 La Ley 387 de 1997 establece a los desplazados como las personas que cumplen con las siguientes características: "Es desplazado toda persona que se ha visto forzada a migrar dentro del territorio nacional abandonando su localidad de residencia o actividades económicas actuales, porque su vida, su integridad física, su seguridad o libertad personal han sido vulneradas o se encuentran directamente amenazadas, con ocasión de cualquiera de las siguientes situaciones: conflicto armado interno, disturbios y tensiones interiores, violencia generalizada, violaciones masivas de las derechos humanos, infracciones al Derecho Internacional Humanitario otras circunstancias emanadas de las situaciones anteriores que puedan alterar o alteren drásticamente el orden público". 
armados. Aunque identificar las causas subyacentes del fenómeno del desplazamiento no es una tarea fácil pero, es indiscutible que la violencia desatada por el conflicto armado es la principal causa del desplazamiento en la región del Catatumbo. El conflicto afecta a la sociedad civil por medio de amenazas, ataques, acciones militares, reclutamiento y toma de municipios generando así el desplazamiento reactivo de la población (ante un evento concreto que haya afectado al hogar) o preventivo (para evitar los eventos violentos relacionados con el conflicto armado) ${ }^{3}$.

Si bien la causa principal del desplazamiento es la violencia originada por el conflicto armado, es importante observar los detonantes del desplazamiento, es decir los motivos que inducen a la movilización inmediata de la población.

\section{Propiedad de la tierra}

Los trabajos de Reyes y Bejarano (1998) y Erazo (2000) coinciden en señalar la importancia de la tierra como causa del desplazamiento. En efecto, los intereses económicos de los actores armados conllevan en muchos casos a la apropiación violenta de la tierra, despojando a los pobladores de uno de sus principales medios de subsistencia. La importancia de la tierra dentro del grupo de población desplazada es evidente en el trabajo de Erazo (2000) en donde cerca del 50 por ciento de los hogares encuestados reportaron poseer o arrendar tierras en su lugar de origen y cerca del 80 por ciento de éstos hogares dependen de la tierra para su sustento.

Cerca del 60 por ciento de los hogares poseedores de tierras reportaron ser propietarios y en la mayoría de los casos, los predios fueron apropiados por la fuerza o abandonados lo cual contradice algunas hipótesis según las cuales los hogares desplazados lograban vender sus tierras a un muy bajo costo antes de abandonarlas.

Lo que sí se conoce es la variedad de modalidades utilizadas por los grupos armados para ser los dueños de miles de hectáreas, la mayoría ricas en recursos agropecuarios, energéticos, hídricos y bio-ambientales como es el caso de la región del Catatumbo que desarrolla mega proyectos para la región en (carbón y petróleo).También avanza la siembra de la palma africana y de cacao, esta región ha recibido de la agencia de cooperación CAPP/ARD \$1.963.847.625 para cacao y $\$ 122.005 .311$ para palma de aceite, con el propósito de fortalecer la asistencia técnica de los proyectos alternativos. Las comunidades tienen la esperanza de que estos cultivos generen riqueza y progreso para la zona, aunque se prevé que al mismo tiempo podrían generar inestabilidad y un aumento de la violencia. Algunas de las prácticas que se pudieran desencadenar serian: El testaferrato, La venta ilegal de tierras-estafa, Escritura sin registro, Venta de tierras a bajo precio, bajo presión, Fragmentación de la tierra.

\footnotetext{
3 Algunos autores como Meertens (1999) e Ibáñez y Vélez (2003) señalan que el desplazamiento preventivo podría predominar sobre el reactivo, en particular, en zonas de violencia.
} 


\section{Narcotráfico y cultivos ilícitos}

El narcotráfico y la presencia de cultivos ilícitos en las diferentes regiones del país presentan una estrecha relación con el fenómeno del desplazamiento. Reyes $(1996,1997)$ y Pérez (2002) mencionan dos casos particulares que vale la pena resaltar. Por un lado, la compra de tierras por narcotraficantes como mecanismo para lavar dinero ilícito, genera un proceso especulativo de la tierra, que diezma la capacidad de adquisición del Estado y las posibilidades de negociación de los campesinos frente a los terratenientes. Además, los narcotraficantes heredan en muchos casos conflictos sociales en las tierras que compran, para lo cual conforman grupos de autodefensa que intensifican el conflicto en la región y desde luego, el desplazamiento ${ }^{4}$.

La presencia de cultivos ilícitos genera una presión adicional sobre la tierra y sobre el desplazamiento debido no sólo a la adquisición de tierras para el cultivo de coca y amapola sino también por la importancia del control de corredores para el transporte de drogas y armamento. La fumigación de cultivos ilícitos implica, así mismo, la destrucción de los activos de los cultivadores, generando un choque en sus ingresos y un incremento en los combates. La intensificación de la fumigación en los últimos años ha provocado una ola migratoria importante. La erradicación de estos cultivos ha contribuido, según CODHES (Consultoría para los Derechos Humanos y el Desplazamiento), al desplazamiento de personas desde 1998.

Se presume que los cultivos de coca aparecen en el Catatumbo hacia 1992 y crecen rápidamente debido a factores como: las condiciones agrológicas, los bajos costos de los insumos y disponibilidad inmediata, facilidad de transporte, excelente posición estratégica, abundante mano de obra, fácil lavado de dólares, situación de pobreza de campesinos, zona de frontera con una llanura abierta difícil de controlar, entre otros.

El primer dato estadístico de los cultivos de coca es del año de 1994, cuando se detectaron cerca de 350 hectáreas de coca. Según la Dirección Antinarcóticos de la Policía Nacional, para el año 2000, 4.660 hectáreas de coca afectaban los Parques Nacionales Naturales, entre ellos el Parque Motilón-Bari en la región del Catatumbo. Las cifras sobre la deforestación que generan los cultivos de uso ilícito, las cuales datan desde 1992, no tienen un sustento científico riguroso, sin embargo, bajo esa premisa, ACODAL señala que el $79 \%$ de la deforestación en el país se debe a estos cultivos ${ }^{5}$.

\footnotetext{
4 Como lo señala Pérez, que la presión sobre la tierra y los conflictos que esto genera se presenta en zonas en las cuales haya presencia de recursos estratégicos, no sólo cultivos ilícitos, sino también carbón, petróleo y esmeraldas, generando especulación y violencia.

5 Álvarez, (2001), y ACODAL (2002) comentan sobre los daños ambientales por cultivos ilícitos y procesamiento de drogas prohibidas en Colombia.
} 
Los cultivos ilícitos ocasionan daños al medio ambiente, desestabilizando la actividad económica campesina tradicional, abandonando sus actividades agrícolas tradicionales y poniendo en grave riesgo la unidad familiar. El cultivo de coca, viene afectando la cultura de la gente, su dedicación a cultivos tradicionales y ganadería, que hoy en día son poco rentables por el difícil acceso al crédito, mínimos niveles de comercialización, falta transferencia de tecnología y asistencia técnica, y con unas vías inadecuadas, que conllevan al desestimulo de la producción de cultivos tradicionales y haciéndolos pocos atractivos, por lo que los agricultores se inclinan hacia la actividad ilícita.

Tibú, cuenta con 10.000 hectáreas cultivos ilícitos aproximadamente y este fenómeno se ha expandido casi por todo su territorio. Los niveles de estas áreas son altos, pues se encuentran predios de 40 hectáreas y más, con áreas mínimas de 1 hectárea; con rangos de cultivos entre 20 a $40 \mathrm{Ha}$. (grandes productores); de 5 a $20 \mathrm{Ha}$. (medianos productores) y de 1 a $5 \mathrm{Ha}$. (pequeños productores), con unos 1.350 productores. En Norte de Santander existen aproximadamente unas 35.000 hectáreas de cultivos ilícitos, que han sido identificadas por los municipios a través de observaciones hechas por los funcionarios de la UMATA (Unidad Municipal de Asistencia Técnica Agropecuaria). Actualmente existen en la Región del Catatumbo unos 2.600 productores dedicados al cultivo de la coca, de los cuales $1.350(52 \%)$ corresponden al Municipio de Tibú en la zona plana.

\section{Desmembramiento de redes sociales}

El desplazamiento es una estrategia para desarticular la acción social, redes de amigos, las redes vecinales y un elemento para intimidar la población como estrategia de guerra, con el fin de atacar al enemigo vulnerando su población de base (Henao 1998). Según Lozano y Osorio (1999), el 65 por ciento de la población desplazada pertenece a organizaciones comunitarias, juntas de acción comunal, cooperativas de productores y tan solo un 11 por ciento a agremiaciones sindicales o políticas.

El desmembramiento de redes sociales por el conflicto armado tiene como fin el empoderamiento del territorio y de sus pobladores para crear o formar su propia base social en busca de sus intereses.

En el escenario comunitario, las comunidades residenciales y las poblaciones largamente establecidas se desorganizan, a la vez que a menudo se dispersan los grupos de parentesco y los sistemas familiares, quedando fuera de operación las vitales redes sociales informales que se proporcionan ayuda mutua. Por este rompimiento de redes sociales las comunidades quedan sin ningún tipo de recurso que les ayude a mitigar la presión y violación de sus derechos. 


\section{CONSECUENCIAS DEL DESPLAZAMIENTO EN EL CATATUMBO}

\section{Pérdida de capital humano}

Aunque el desarrollo integral de un individuo no depende exclusivamente de la educación, es claro que la exclusión de este derecho implica negarle la posibilidad de desarrollarse plenamente como ser individual y social, con influencia negativa para el logro de metas y disfrute del resto de sus derechos como ser humano.

Es de gran importancia que niños, niñas y jóvenes disfruten plenamente de este derecho en términos de oportunidades de acceso, permanencia, y calidad. Lo realmente difícil es que, el Estado y sociedad otorguen en la práctica la prioridad a este derecho, en especial cuando se trata de restituirlo o hacerlo real para poblaciones de desplazados, y víctimas de la violencia.

La educación contiene dos elementos esenciales para el desarrollo del ser humano, sin duda es un medio para aumentar las habilidades y destrezas productivas para las personas y sus ingresos, además es un fin y es fuente directa de enriquecimiento personal, la educación permite a las personas "la posibilidad de leer, argumentar, comunicar, elegir con mayor información, ser tenida en cuenta más seriamente por otros"6. El primer elemento corresponde al capital humano y el segundo a la capacidad humana.

Los anteriores dos elementos son diferentes pero se relacionan en tanto que su punto de estudio es el ser humano como principal actor. Dadas sus características personales, sus antecedentes sociales sus circunstancias económicas, una persona tiene la oportunidad de ser y hacer cosas las cuales considera valiosas para su vida. Esta valoración puede concebirse de forma directa su desarrollo puede enriquecer su vida de forma inmediata como el estar bien alimentado, saludable, o de forma indirecta el cual puede contribuir a la producción futura.

El elemento capital humano puede en principio contener los dos tipos de valoración pero usualmente se enmarca en el indirecto es decir las cualidades humanas que se pueden emplear como capital en la producción tal como se emplea el capital físico. En tanto la percepción del capital humano puede incluirse dentro de la perspectiva de las capacidades humanas que es más amplia y a su vez, esta incluye tanto la valoración indirecta como la directa de las habilidades humanas.

Adam Smith, plantea en su visión del desarrollo económico y social, en la riqueza de las naciones y en la teoría de los sentimientos morales, la importancia de la educación, de la

6 Sen, Amartya (1996), Capital Humano y Capacidad Humana, en: Cuadernos de Economía 29, Universidad Nacional de Colombia. Bogotá, Segundo Semestre 1998. pp. 67-72. 
división del trabajo, del aprendizaje por la experiencia y de la formación técnica en los determinantes de las posibilidades de producción, es muy importante el desarrollo de la capacidad humana para llevar una vida mas digna y para ser más productivos. Smith creía en el poder de la educación y del aprendizaje para el mejoramiento de las capacidades humanas. ${ }^{7}$

Aunque existe gran relación entre los dos elementos anteriormente mencionados, es importante aclarar que son diferentes, una discrepancia significativa entre estas dos perspectivas, es la distinción entre medios y fines, la importancia de las cualidades humanas en cuanto al crecimiento económico por importante que sea, en si no nos dice nada acerca de por qué lo primero que se busca es el crecimiento, si en cambio se da énfasis a la expresión de la libertad humana para vivir el tipo de vida que la gente juzga valiosa, por tanto el papel del crecimiento económico en la expansión de esas oportunidades debe ser integrado a una comprensión más profunda del proceso de desarrollo como la expansión de la capacidad humana para llevar una vida mas libre y justa. ${ }^{8}$

Smith en su polémica con David Hume, afirma que cuando se considera a los seres humanos únicamente desde el punto de vista de su utilidad se menosprecia la naturaleza humana: "Parece imposible que la aprobación de la virtud sea un sentimiento de la misma especie que la aprobación de un edificio cómodo o bien construido, o que no tengamos otra razón para elogiar a un hombre distinta de la que usamos para alabar un armario" 9 . Es importante considerar la expansión de las capacidades para generar un cambio social, no debe entenderse la capacidad tan solo como medio de producción sino adherirse al desarrollo social en busca de participación de excluidos y reducción de la desigualdad.

El conflicto armado en la región del Catatumbo ataca ambos elementos de la educación, pérdidas de capital humano y destrucción de las capacidades, uno de los mayores daños del conflicto armado es "hace valer la fuerza sobre la razón, la coerción sobre la convicción, el fusil sobre el argumento"; y nos enseña a todos que en la vida

\footnotetext{
7 Smith (1976), pág. 28-29 debate entre naturaleza y educación: La diferencia de talentos naturales entre los hombres es, en realidad, mucho menor de lo que creíamos y las diferentes habilidades especiales que parecen distinguir a los hombres de diferentes profesiones cuando llegan a la madurez no son, la mayoría de la veces, la causa son en efecto de la división del trabajo. La diferencia entre las mas disimiles, entre un filosofo y un estibador, por ejemplo, no procede tanto de la naturaleza como del hábito, la costumbre o la educación. Cuando vinieron al mundo y durante los primeros seis u ocho años de existencia eran, quizá muy parecidos, y ni sus padres y compañeros podían advertir ninguna diferencia notoria.

8 Sen, A. (1983) 'Development: Which Way Now?, Economic Journal 93, 1985 Commodities' and Capabilities', North Holland Amsterdam.

${ }_{9}$ Apreciación de Adam Smith sobre la naturaleza humana.
} 
pública y en la vida diaria no cuenta de qué lado está la justicia sino de qué lado están las armas. ${ }^{10}$

El desplazamiento genera desestabilización educativa ya que niños, niñas y jóvenes sufren alteraciones en su ciclo escolar al tener que salir de forma inmediata de su localidad perdiendo las esperanzas de educarse, por ende se presenta perdida y alteración de Capital Humano, además se adiciona, que los miembros del hogar adquieren a lo largo de su vida conocimientos habilidades, y capacidades para el desempeño en especial de actividades agrícolas y cuando ocurre el desplazamiento estas capacidades o especialización carecen de oportunidades para hacerlas útiles y lograr ingresos que les generen un mayor bienestar, las cuales, no encuentra aplicabilidad en los sitios receptores y al ocuparse en actividades en el sector informal urbano se genera una perdida y disminución de ingreso. Por otro lado, la deserción escolar después del desplazamiento, significa la interrupción de la educación de los niños y jóvenes truncando o atrasando las posibilidades de formación y acumulación de Capital Humano para la economía y la sociedad.

El conflicto armado niega la posibilidad de educarse comparando variables entre municipios que presentan actividad armada de grupos ilegales y municipios similares sin dicha actividad, Sánchez y Díaz, (2004) ${ }^{11}$ estimaron en forma indirecta el efecto del conflicto armado sobre el desarrollo social. Estos autores encuentran que el incremento de la violencia ha incidido notoriamente en el crecimiento de la deserción y la inasistencia escolar. Los municipios que registraron actividad de las Farc tuvieron un crecimiento anual de la matrícula primaria de $1,11 \%$ y de la matrícula secundaria de $2,22 \%$. En cambio, los municipios que no padecieron acciones de esta guerrilla en ese período presentaron aumentos de matrícula primaria y secundaria de 2,58\% y 4,22\% respectivamente.

En el caso del Eln, los efectos indirectos de su actividad sobre la matrícula primaria y secundaria no resultaron estadísticamente significativos y en el caso de las Autodefensas los municipios que registraron actividades de estos grupos tuvieron un crecimiento anual de la matrícula primaria y secundaria de $0,75 \%$ y $2,70 \%$ respectivamente, mientras que los municipios que no registraron actividades de estas organizaciones tuvieron crecimientos promedio anual de $1,18 \%$ en matrícula primaria y de $3,34 \%$ en secundaria.

\footnotetext{
10 PNUD (2003), Informe Nacional de Desarrollo Humano Colombia; El Conflicto, Callejón con Salida, Bogotá. p. 105.

11 Estos autores afirman que "Los Efectos del Conflicto Armado en el Desarrollo Social Colombiano". Universidad de los Andes. Bogotá, septiembre documento CEDE.. Las "actividades" de los grupos armados ilegales (Farc, Eln, Auc), consideradas son: acciones terroristas, emboscadas, hostigamientos entre otros.
} 
Estos resultados son compatibles con los cálculos del Programa Nacional de Desarrollo Humano hechos para El Conflicto, Callejón con Salida según los cuales la tasa de deserción escolar es mayor en los municipios con presencia tanto de guerrillas como de paramilitares $(9,84 \%)$, un poco menor en aquellos con presencia guerrillera $(8,72 \%)$ o paramilitar $(7,84 \%)$ y aún menor en los que no se registra actividad de grupos armados ilegales $(7,72 \%)^{12}$.

Según PNUD, "los departamentos con más alto índice de abandono escolar son también aquellos con más altos índices de reclutamiento", por tanto crea deserción escolar ésta crece si la pertinencia y flexibilidad de los currículos escolares es baja y si el costo de oportunidad de la educación es muy alto dada la pobreza de los hogares.

Las personas en edad escolar y en situación de desplazamiento no sólo enfrentan las dificultades propias de la deserción obligada en sus sitios de origen, sino la deserción del sistema educativo. Esto es así porque en las localidades receptoras de población desplazada ésta no encuentra garantizado su derecho a cupos preferenciales en colegios públicos ni a ser exonerados de los costos de matrículas y pensiones. Adicionalmente, los niños niñas y jóvenes en situación de desplazamiento enfrentan problemas psicosociales, nutricionales, habitacionales que conspiran contra su rendimiento escolar. La deserción del sistema educativo se transforma rápidamente por cuenta de la carencia de ingresos de las familias desplazadas, en nuevos casos de trabajo infantil, Ibáñez, y Vélez (2003) ${ }^{13}$.

Es necesario que las políticas públicas introduzcan bienestar, libertad, prosperidad, para el goce de la vida, además que el presupuesto dirigido a este fenómeno sea menos indiferente a los nuevos desafíos que enfrentan los municipios receptores de población desplazada. Por tanto la distribución de recursos del sector educativo es importante para el desarrollo de las políticas Estatales, además se debe tener en cuenta los cambios poblacionales causados por el conflicto, pero más importantes aún son los cambios institucionales que se requieren para poner las políticas Estatales en sintonía con la realidad de cada localidad en conflicto.

En materia educativa es necesaria una descentralización flexible y programas para poder hacer frente a los diversos canales de transmisión del conflicto hacia la educación. Aunque el plan sectorial de la Revolución Educativa contempla abrir 640 mil cupos para población vulnerable (personas desplazadas, población indígena, niños con limitaciones o discapacidades y población de zonas rurales con baja densidad) financiados con recursos provenientes del Fondo Nacional de Regalías, el único

12 PNUD (Programa de las Naciones Unidas para el Desarrollo). op.cit. p 107.

${ }_{13}$ Dan crítica de los Instrumentos de Atención de la Población Desplazada en Colombia: Una

Distribución Desigual de las Responsabilidades Municipales. Universidad de los Andes. Bogotá, diciembre documento CEDE. 
elemento nuevo de flexibilidad que introduce para hacer frente a la dispersión y la movilidad de dicha población es el de la contratación del servicio educativo con instituciones eclesiásticas, colegios, cooperativas y corporaciones seleccionadas mediante concurso ${ }^{14}$.

Esto es insuficiente ante la variedad, complejidad y magnitud de los canales de transmisión que van del conflicto armado al cierre de la opción de ir a la escuela. La población vulnerable definida por el plan sectorial de la Revolución Educativa debería incluir a los niños, niñas y jóvenes víctimas del conflicto armado y no sólo a la población desplazada en edad escolar. Así mismo, dado que el grueso de las víctimas está en el campo, la población rural incluida como vulnerable no debe estar restringida a los habitantes de zonas con baja densidad poblacional.

Según el Programa Transformamos que efectúa "Petróleo sin analfabetismo combustible para el desarrollo" se esta aplicando en la región del Catatumbo cerca de 10 mil niños, de los 22 mil que no estudian en la zona del Catatumbo por causa de la violencia y la falta de recursos este se ha implementando en los diez municipios del Catatumbo desde el año 2005, momento en el cual la región presentaba un índice de analfabetismo del 34,92\% para las personas mayores de 13 años, el 38,3\% de los jóvenes no asistía a una institución educativa, el 50\% de los habitantes había cursado algún grado de primaria y el 10\% había adelantado algún grado de secundaria.

\section{Alteración en el mercado laboral}

El cambio de ocupación de las personas antes y después del desplazamiento, significa que agentes económicamente productivos y por lo general autónomos en actividades ligadas en especial a la agricultura, pasan a engrosar el sector informal desempeñando oficios de muy baja productividad y mínima remuneración, que no generan valor agregado. Por otro lado, este proceso produce a su vez cambios en los roles al interior de las familias desplazadas así: los hombres abandonan su rol como principales generadores de ingresos, mientras las mujeres se insertan en el mercado laboral informal.

Las condiciones laborales adversas son, en gran medida, resultado de las características de la población desplazada, en especial de los bajos niveles de escolaridad, su proveniencia rural y de sus habilidades agrícolas, las cuales no son atractivas en los mercados laborales urbanos.

Las tasas de desempleo de los jefes de hogar y de los otros miembros del hogar mayores de 18 años aumentan después del desplazamiento, el porcentaje de jefes del hogar desempleados aumenta del 1.7 por ciento en el municipio de origen al 16.1 por

\footnotetext{
14 Ministerio de Educación Nacional "Revolución Educativa. Plan Sectorial 2002-2006”.
} 
ciento en el receptor. Para los otros miembros del hogar hay también un incremento significativo en las tasas de desempleo como consecuencia del desplazamiento: mientras la tasa de desempleo para estos miembros del hogar era de sólo el 6.9 por ciento en los municipios de origen, en los municipios receptores llega a ser del 12 por ciento. Además, mientras que en los municipios de origen las tasas de desempleo para los jefes del hogar eran menores que aquellas de la población pobre e indigente en los municipios receptores se revierte esta situación, ya que los jefes de hogar presentan índices de desempleo similares a aquellos de hogares indigentes. Por el contrario, si bien las tasas de desempleo aumentan para otros miembros de los hogares desplazados, estas continúan siendo menores a aquellas de los hogares pobres e indigentes.

El desplazamiento hace a los hogares más vulnerables frente a la pobreza ya que aún para aquellos hogares que llevan viviendo más de un año en los municipios receptores, el desempleo en la población desplazada es mayor que en la población pobre urbana. Para aquellos hogares que llevan menos de tres meses de ser desplazados la tasa de desempleo para los jefes de hogar y otros miembros es del 53 y 33 por ciento respectivamente, mientras que para los hogares que llevan más de un año de ser desplazados las tasas de desempleo son considerablemente menores; 16 y 14 por ciento respectivamente Ibáñez y Querubín (2004).15

Los mercados laborales urbanos, con una demanda casi nula por habilidades agrícolas, obligan a la población desplazada a cambiar su ocupación laboral y a trabajar en empleos informales con condiciones precarias. La mayoría de los desplazados provienen de áreas rurales en donde dos terceras partes de los jefes de hogar estaban vinculados al sector agrícola. En los municipios receptores estos se ven obligados a abandonar sus actividades habituales ya que menos de una tercera parte logra vincularse a alguna actividad agrícola, esta situación es más evidente para los hombre, ya que la mayoría de ellos están entrenados en labores agrícolas y sus conocimientos y capacidades no son relevantes ni transferibles para las labores que se ofrecen en las áreas urbanas. Como resultado, mientras que en los municipios de origen los hombres jefes de hogar se dedicaban a estas actividades, sólo una reducida muestra puede hacerlo en el municipio de recepción.

Por último, es posible observar que el desplazamiento genera un choque negativo sobre el ingreso laboral de los hogares. Mientras que en los municipios de origen el ingreso laboral por adulto es bien remunerado, en el municipio receptor este ingreso desciende; es decir que después del desplazamiento los hogares reciben menos de la mitad del ingreso que devengaban en los municipios de origen.

15 Conclusión de estudio, “desplazamiento forzado en Colombia” Mayo de 2004, documento CEDE. 
Así mismo, estudios establece que aún cuando los desplazados encuentran empleo, éste está caracterizado por requerir pocas habilidades, un alto grado de informalidad y, por ende, en condiciones precarias e ingresos bajos e inestables.

\section{CONCLUSIONES}

En la últimas dos décadas Norte de Santander experimentó tanto un crecimiento sostenido como una expansión territorial de todos los tipos de actividad de los armados grupos ilegales en especial en la región de Catatumbo llegando a afectar una porción significativa de los municipios a su alrededor. Los efectos económicos y sociales del conflicto interno han sido considerables. En esta investigación se analizaron las consecuencias sobre algunos indicadores de desarrollo social como lo es la perdida de capital humano y alteración en el mercado laboral, que sin duda alguna son elementos que restringen el desarrollo directo de una sociedad.

El principal factor del conflicto armado en la región se ha construido por la disputa entre las fuerzas armadas tanto regulares como irregulares por el control de la zona que representa sin duda grandes ventajas estratégicas por posición de frontera, el paso del oleoducto de caño Limón Coveñas; la producción de cultivos ilícitos las explotaciones carboníferas y de petróleo. Además, en los últimos años el desarrollo de proyectos agroindustriales de la palma de aceite y la existencia de corredores estratégicos los cuales comunican el oriente con el norte del país y la cercanía en el norte con la Serranía de Perijá que provee un salida hacia los departamentos de la Guajira, Bolívar, y Cesar, además la escasa conexión con el Estado que permite la sustitución de un poder nacional y local por otro meramente clientelista y gamonalicio.

Los diferentes hechos presentados permiten hacer una valoración de cómo el conflicto armado produce de manera directa el desplazamiento; fenómeno social que se encuentra altamente ligado a la presión por el control de tierras, narcotráfico, sobre todo en sub-regiones que presentan un gran nivel de recursos mineros o agroindustriales.

Sin duda estas disputas por apoderarse de territorios y por ende lograr consolidar una base social sólida generan de manera directa desplazamiento, ciento de familias enfrentan condiciones socioeconómicas graves. Por un lado, los hogares fueron desplazados, por lo general, debido a situaciones de violencia directa con graves repercusiones psicológicas. De otro lado, su capacidad para adaptarse a los lugares de recepción es reducida puesto que su nivel de escolaridad es bajo y cuentan con poco conocimiento de su nueva ciudad. Como consecuencia, la vinculación al mercado laboral es escasa y la asistencia educativa es insuficiente. Todo esto ocasiona una 
condición de fragilidad extrema para el hogar desplazado y los puede inducir a un espiral de pobreza; el cual muy posiblemente no podrán superar en un futuro cercano.

En términos generales, el conflicto armado ha tenido efectos desfavorables para el desarrollo de la región, al ser el causante del desplazamiento el cual a su vez genera condiciones inhumanas para el disfrute y posicionamiento en la sociedad que les permita acceder a lo que ellos consideran valioso para una vida digna y justa además, conlleva a condiciones adversas sobre la acumulación de capital físico ataques a la infraestructura, de capital humano violencia homicida, fuga de capital humano y menor cobertura escolar y alteración en el mercado laboral, y además efectos colaterales como la cohesión social, el aumento en los costos de transacción costos de transporte, deterioro institucional, corrupción e impunidad judicial.

Así mismo, el crecimiento en la matrícula de los niveles primaria y secundaria fue menor en los municipios que presentan actividad armada. De hecho, las consecuencias sobre los alumnos matriculados en primaria fueron considerables, ya que si no se hubiese presentado actividad armada, se hubieran matriculado alumnos adicionales, cerca de un $7 \%$ adicional a los que se matricularon. En el mismo sentido, las consecuencias de las condiciones y el contexto generado por la actividad armada sobre los alumnos matriculados en secundaria son significativas, alrededor del $12 \%$ de pérdida de crecimiento de los alumnos matriculados. Las mayores pérdidas se observaron en los municipios con actividad de las Autodefensas, en los cuales los alumnos matriculados dejaron de crecer cerca de cinco puntos porcentuales promedio municipal anual, lo cual es igual a 491 alumnos menos. Los efectos también fueron importantes en aquellos municipios que sufrieron actividad armada ilegal de las Farc, donde los jóvenes matriculados en secundaria crecieron a una tasa de dos puntos porcentuales inferior que aquellos municipios donde no hubo actividad armada, lo que se traduce en 231 mil alumnos menos.

De acuerdo con la información observada, la expansión y crecimiento de la actividad armada en la región del Catatumbo ha tenido consecuencias significativas para el desarrollo social. Los resultados encontrados son contundentes, e indican que además de los efectos visibles de los ataques de los grupos ilegales que afectan el desarrollo de la población desplazada impidiéndoles el logro de sus metas, y todo esto tienen serias implicaciones aún peores para el desarrollo de largo plazo. 


\section{REFERENCIAS}

- ACODAL (2002) Asociación Colombiana de ingeniería sanitaria y ambiental "Daños ambientales por cultivos ilícitos y procesamiento de drogas".

- Bejarano, Reyes (1998), y Erazo (2000) "Colombia: Importancia de la tierra inseguridad, violencia y desempeño económico en las áreas rurales”, Bogotá.

- CODHES Consultoría+ para los Derechos humanos y el Desplazamiento (2004), "Boletín de la Consultoría para los Derechos Humanos y el Desplazamiento", No 52, www.codhes.org.co.

- Henao (1998) Lozano y Osorio (1999), "Rompimiento de redes sociales".

- DANE (2001-2002) Departamento Administrativo Nacional de Estadísticas.

- Ibáñez, (2001) "Acceso a tierras y desplazamiento forzado en Colombia".

- Ibáñez, Vélez, (2003), Instrumentos de Atención de la Población Desplazada en Colombia: Una Distribución Desigual de las Responsabilidades Municipales. Universidad de los Andes. Bogotá, diciembre Documento CEDE.

- Ibáñez, y Querubín (2004). "Acceso a Tierras y Desplazamiento forzoso en Colombia”. Bogotá, Documento CEDE.

- Ley 387 de (1997) "Plan Nacional de Atención a la Población Desplazada".

- Ministerio de Educación Nacional, "Revolución educativa plan sectorial (2002-2006)".

- Meertens, (1999) e Ibáñez y Vélez (2003) "Desplazamiento preventivo y reactivo".

- Pérez, (2002) "Presiones sobre la tierra y conflictos en zonas con recursos potenciales".

- Pérez, (2002). "Desplazamiento forzado en Colombia 1995-1999: Una aproximación empírica a las relaciones entre desplazamiento, conflicto armado y desarrollo" en El desplazamiento forzado en Colombia: compromisos desde la universidad. Bogotá, Colombia.

- PNUD (2003), "Informe Nacional de desarrollo Humano en Colombia. El conflicto, Callejón sin salida, Bogotá pág. 105.

- PNUD (2004) “Deserción escolar" pàg.107.

- Reyes $(1996,1997)$ y Pérez (2002) "Proceso especulativo de la tierra".

- Sánchez, Díaz (2004), "Efectos del Conflicto Armado en el Desarrollo Social Colombiano" Bogotá, septiembre Documento CEDE.

- Sen, Amartya (1996), "Capital Humano y Capacidad Humana" en: Cuadernos de Economía N 29 Universidad Nacional de Colombia. Bogotá, segundo semestre 1998.

- Sen, Amartya (1983) “Economic Journal 93, 1985 Commodities' and Capabilities', North Holland Amsterdam.

- Smith (1976) debate entre naturaleza y educación pág. 28-29.

- USO, Unión Sindical Obrera de la Industria de Petróleo. 